\title{
Outcomes for endocarditis surgery in North America: A simplified risk scoring system
}

\author{
Jeffrey G. Gaca, MD, ${ }^{a}$ Shubin Sheng, PhD, ${ }^{\mathrm{b}}$ Mani A. Daneshmand, MD, ${ }^{\mathrm{a}}$ Sean O'Brien, $\mathrm{PhD},{ }^{\mathrm{b}}$ \\ J. Scott Rankin, MD, ${ }^{\mathrm{c}} \mathrm{J}$. Matthew Brennan, MD, ${ }^{\mathrm{a}} \mathrm{G}$. Chad Hughes, MD, ${ }^{\mathrm{a}}$ Donald D. Glower, MD, ${ }^{\mathrm{a}}$ \\ James S. Gammie, MD, ${ }^{\mathrm{d}}$ and Peter K. Smith, $\mathrm{MD}^{\mathrm{a}}$
}

Objective: Operation for infective endocarditis is associated with the highest mortality of any valve disease,
with overall rates of in-hospital mortality exceeding $20 \%$. The Society of Thoracic Surgeons Adult Cardiac Sur-
gery Database was examined to develop a simple risk scoring system and identify areas for quality improvement.

Methods: From 2002 through 2008, 19,543 operations were performed for infective endocarditis. Logistic regression analysis related baseline characteristics to both operative mortality and a composite of mortality and major morbidity within 30 days. Points were assigned to each risk factor, and estimated risk was obtained by averaging events for all patients having the same number of points.

Results: Overall unadjusted mortality was $8.2 \%$, and complications occurred in $53 \%$. Significant preoperative risk factors for mortality (associated points) were as follows: emergency, salvage status, or cardiogenic shock (17), preoperative hemodialysis, renal failure, or creatinine level less than 2.0 (12), preoperative inotropic or balloon pump support (10), active (vs treated) endocarditis (10), multiple valve involvement (9), insulindependent diabetes (8), arrhythmia (8), previous cardiac surgery (7), urgent status without cardiogenic shock (6), non-insulin-dependent diabetes (6), hypertension (5), and chronic lung disease (5), with a $\mathrm{C}$ statistic of 0.7578 (all $P<.001$ ). Risk-adjusted mortality and major morbidity were unchanged over the course of the study. In the entire data set, mortality was better if "any valve" was repaired (odds ratio $=0.76 ; P=.0023$ ).

Conclusions: Operative mortality for surgically treated infective endocarditis is substantially lower than reported in-hospital mortality rates for infective endocarditis. The described risk scoring system will inform clinical decision-making in these complex patients. (J Thorac Cardiovasc Surg 2011;141:98-106)

Supplemental material is available online.

Despite advances in medical and surgical therapy, the incidence of infective endocarditis (IE) has not decreased over the past 30 years. ${ }^{1}$ In the United States, IE affects approximately 15,000 patients each year with an in-hospital mortality exceeding $20 \% .^{2,3}$ Proper decisions regarding the indications, timing, and performance of cardiac surgery in patients with IE have the potential to further reduce the morbidity and mortality from this challenging disease.

From Duke University Medical Center, ${ }^{\text {a }}$ Durham, NC; The Society of Thoracic Surgeons Adult Cardiac Surgery Database, ${ }^{\mathrm{b}}$ Durham, NC; Vanderbilt University Medical Center, ${ }^{\mathrm{c}}$ Nashville, Tenn; and University of Maryland Medical Center, ${ }^{\mathrm{d}}$ Baltimore, Md.

Disclosures: Authors have nothing to disclose with regard to commercial support.

Read at the 36th Annual Meeting of The Western Thoracic Surgical Association, Ojai, California, June 23-26, 2010.

Received for publication June 21, 2010; revisions received Aug 10, 2010; accepted for publication Sept 19, 2010.

Address for reprints: Jeffrey G. Gaca MD, Duke University Medical Center, DUMC Box 2816, Durham, NC 27710 (E-mail: jeffrey.gaca@duke.edu). 0022-5223/\$0.00

Published by Elsevier Inc. on behalf of The American Association for Thoracic Surgery

doi:10.1016/j.jtcvs.2010.09.016
Increases in several risk factors, including an expansion of the elderly population with degenerative valve disease and a rise in staphylococcal infections, suggest that IE will remain a significant health problem in the future. ${ }^{4}$ Surgical therapy remains an invaluable intervention in the treatment of IE, yet it also carries the highest mortality of any surgical intervention for heart valve disease. ${ }^{5-7}$ An opportunity may exist to improve the care of patients with IE by optimizing the timing and application of surgical therapy. ${ }^{8}$

Little is known about the surgical risk factors and optimal patient selection in patients with IE. ${ }^{9}$ The clinical scenarios encountered by surgeons, patients, and their families are often very complex and require rapid decision-making involving high-risk surgery without adequate data. Given the relatively small number of cases of IE at an individual institution, obtaining large numbers of patients for study can be difficult. The Society of Thoracic Surgeons Adult Cardiac Surgery Database (STS ACSD) provides an excellent opportunity to study large numbers of patients undergoing surgery for IE. Surgical outcomes of selected groups of patients with IE in the STS ACSD, such as mitral valve subgroups or those with dialysis-dependent renal failure, have been studied previously, but the characteristics of the entire cohort of patients with IE have not been defined. ${ }^{6}$ 


\section{Abbreviations and Acronyms \\ ACSD $=$ Adult Cardiac Surgery Database \\ IE = infective endocarditis \\ STS $=$ The Society of Thoracic Surgeons}

Therefore, the purpose of this study was to examine the STS ACSD to (1) identify risk factors that influence operative morbidity and mortality in surgery for IE and (2) use these risk factors to develop a simple bedside scoring system for clinical decision-making.

\section{METHODS}

\section{Data Set}

The STS ACSD was established in 1989 and includes data from nearly 3 million cardiac surgical operations from over $90 \%$ of cardiac surgical centers in North America. ${ }^{10}$ Patient variables are entered using uniform definitions and a dedicated software system, and data storage and analysis are performed at the Duke Clinical Research Institute. The population for this study consisted of all patients with the diagnosis of IE who underwent surgery on the aortic, mitral, and/or tricuspid valves at STS participating hospitals between 2002 and 2008. This era was selected because it represented a large patient population with the most complete data available in the STS ACSD. Data were collected using the forms provided at http://www.sts.org/doc/8428. The total number of valvular surgical procedures in the STS ACSD during the study period was 416,227. Of these, $19,730(4.7 \%)$ valvular procedures were performed for IE, and this group forms the study population. Sites were excluded if data were missing on age $(0.05 \%)$, gender $(0.04 \%)$, status of surgery $(0.11 \%)$, cardiogenic shock $(0.13 \%)$, and endocarditis type $(0.70 \%)$. Sites also were excluded if more than $20 \%$ of patients had no complication information reported $(0.17 \%)$. If any of the sites failed to meet these criteria on data reporting, the entirety of their data was excluded.

Preoperative characteristics and postoperative complications were entered in the data set as defined in the STS data forms. Formal STS definitions include the following: If the patient is currently being treated for endocarditis, the disease is considered active. If no antibiotic medication (other than prophylactic medication) is being given at the time of surgery, then the infection is considered treated. Operative status is considered elective if the patient's cardiac function has been stable in the days or weeks before the operation and the procedure could be deferred without increased risk of compromised cardiac outcome. Urgent status means that the procedure is required during the same hospitalization to minimize chance of further clinical deterioration. Emergency status means the patient requiring emergency operations will have ongoing, refractory (difficult, complicated, and/or unmanageable) unrelenting cardiac compromise, with or without hemodynamic instability, and not responsive to any form of therapy except cardiac surgery. An emergency operation is one in which there should be no delay in providing operative intervention. Additional STS definitions of the preoperative variables and postoperative complications are available at http://209.220.160.181/STSWebRiskCalc261/support_definitions.html.

\section{Statistical Analysis}

Seventy percent of the data $(n=13,617)$ was randomly selected to develop the risk score model with the remaining $30 \%(n=5926)$ reserved for model validation. Baseline characteristics and clinical event rates were described using medians with 25 th and 75 th percentiles for continuous variables and frequencies and proportions for categorical variables. Descriptive data were compared using the Wilcoxon rank-sum test for continuous and ordinal variables and a Pearson $\chi^{2}$ or Fisher's exact test for categorical variables. Multivariable logistic regression was performed to establish 2 different scoring systems. The first logistic regression was performed to assess the association between preoperative characteristics and the risk of operative mortality. A second logistic regression was performed to assess the association between preoperative characteristics and a composite end point of death and major complication. The study composite end point was defined as any of the following postoperative events occurring before discharge or within 30 days of surgery: death, deep sternal wound infection, postoperative stroke, prolonged ventilation, pneumonia, renal failure, dialysis, multisystem organ failure, and readmission within 30 days.

Covariates were selected on the basis of univariable analysis and previous STS model variables. Data were fit in the logistic regression using a generalized equation estimation to account for within-site correlation. A parsimonious subset of 14 variables was selected that explained more than $93 \%$ of the variation in the full model. To create a simplified risk scoring system, we multiplied regression coefficients from the simplified model by a factor of 15 and then rounded them to the nearest integer. Because the data used in analyses of the STS ACSD represent a limited data set (no direct patient identifiers) that was originally collected for nonresearch purposes, and the investigators do not know the identity of individual patients, the analysis of these data was declared by the Duke University Health System Institutional Review Board to be research not involving human subjects and is therefore considered exempt. ${ }^{11}$ All statistical analyses were performed using SAS version 8.2 software (SAS Institute, Cary, NC).

\section{RESULTS}

Patient demographics are listed in Table 1. The median age of patients undergoing surgery for IE was 55 years (45-66 years) and the majority of patients were male $(66.7 \%)$. Reflecting the severity of illness of patients with IE, $23.3 \%$ of the patients were in renal failure with $13.3 \%$ receiving renal dialysis. Over half $(51.5 \%)$ of the patients undergoing surgery for IE were classified as having active endocarditis at the time of surgery. Again, active endocarditis is defined by the STS as any patient currently receiving antibiotic therapy at the time of surgery. Patients receiving routine prophylactic antibiotics for surgery were not included. Preoperative stroke (defined as a neurologic deficit lasting more than 24 hours) was present in $18.9 \%$ $(\mathrm{n}=2580)$ of patients in the study. In this group of patients with preoperative stroke, $29.4 \%(n=759)$ were classified as having recent stroke (within 2 weeks of surgery) and $67.1 \%(\mathrm{n}=1732)$ were classified as having had remote strokes ( $>2$ weeks before surgery). Previous cardiac surgery was present in the study as prior coronary artery bypass grafting $(7.9 \%)$, prior valve surgery $(20.5 \%)$, or other prior cardiac surgery $(3.9 \%)$. The total percentage of patients undergoing redo surgery for IE was $32.9 \%(n=4480)$. Valvular dysfunction included mitral insufficiency $(54.17 \%)$, aortic insufficiency $(40.65 \%)$, and tricuspid insufficiency $(16.30 \%)$.

The operative statistics and complications are listed in Table 2. Of the total 13,617 surgical procedures analyzed for the risk model, the majority were classified as urgent $(49.8 \%)$. The operations were documented as elective in $42.95 \%$ of patients with $6.79 \%$ classified as emergency and $0.49 \%$ classified as salvage. In the overall population, 
TABLE 1. Distribution of baseline characteristics

\begin{tabular}{|c|c|c|c|}
\hline Variable & Level & $\mathbf{N}$ & $\begin{array}{c}\text { Overall } \\
(\%)\end{array}$ \\
\hline \multirow[t]{4}{*}{ Age (y) } & Median & 13617 & 55.00 \\
\hline & 25 th & & 45.00 \\
\hline & 75 th & & 66.00 \\
\hline & Mean & & 55.11 \\
\hline \multirow[t]{2}{*}{ Gender $(\%)$} & Male & 9092 & 66.77 \\
\hline & Female & 4525 & 33.23 \\
\hline \multirow[t]{5}{*}{ Race $(\%)$} & White and others & 10593 & 77.79 \\
\hline & African American & 2113 & 15.52 \\
\hline & Hispanic & 624 & 4.58 \\
\hline & Asian & 235 & 1.73 \\
\hline & Mixed & 52 & 0.38 \\
\hline \multirow[t]{7}{*}{ Surgery year $(\%)$} & 2002 & 1247 & 9.16 \\
\hline & 2003 & 1765 & 12.96 \\
\hline & 2004 & 1799 & 13.21 \\
\hline & 2005 & 2068 & 15.19 \\
\hline & 2006 & 2412 & 17.71 \\
\hline & 2007 & 2404 & 17.65 \\
\hline & 2008 & 1922 & 14.11 \\
\hline \multirow[t]{4}{*}{ Body surface area $(\%)$} & $<1.5$ & 494 & 3.63 \\
\hline & $\geq 1.5$ and $<1.75$ & 2709 & 19.89 \\
\hline & $\geq 1.75$ and $<2$ & 5190 & 38.11 \\
\hline & $\geq 2$ & 5126 & 37.64 \\
\hline Prior tobacco use $(\%)$ & & 7027 & 51.60 \\
\hline \multirow[t]{2}{*}{ Diabetes $(\%)$} & Insulin-dependent & 1504 & 11.05 \\
\hline & Non-insulin-dependent & 1697 & 12.46 \\
\hline Hypercholesterolemia (\%) & & 4867 & 35.74 \\
\hline Renal failure $(\%)$ & & 3174 & 23.31 \\
\hline Preoperative dialysis $(\%)$ & & 1807 & 13.27 \\
\hline Hypertension (\%) & & 7658 & 56.24 \\
\hline Active endocarditis $(\%)$ & & 7022 & 51.57 \\
\hline $\begin{array}{l}\text { Chronic lung } \\
\text { disease/COPD (\%) }\end{array}$ & & 3109 & 22.83 \\
\hline $\begin{array}{l}\text { Immunosuppressive } \\
\text { treatment }(\%)\end{array}$ & & 933 & 6.85 \\
\hline $\begin{array}{l}\text { Peripheral vascular } \\
\text { disease }(\%)\end{array}$ & & 1494 & 10.97 \\
\hline \multirow{2}{*}{$\begin{array}{l}\text { Cerebrovascular } \\
\text { disease }(\%)\end{array}$} & No prior stroke & 596 & 4.38 \\
\hline & Prior stroke & 2580 & 18.95 \\
\hline Arrhythmia (\%) & & 2638 & 19.37 \\
\hline \multirow[t]{3}{*}{ Reoperation (\%) } & 0 previous & 10320 & 75.79 \\
\hline & 1 previous & 2623 & 19.26 \\
\hline & $2+$ previous & 674 & 4.95 \\
\hline Prior CABG $(\%)$ & & 1079 & 7.92 \\
\hline Prior valve surgery $(\%)$ & & 2803 & 20.58 \\
\hline Prior other cardiac surgery $(\%)$ & & 535 & 3.93 \\
\hline Preoperative steroids $(\%)$ & & 962 & 7.06 \\
\hline \multirow{5}{*}{$\begin{array}{l}\text { No. of diseased } \\
\quad \text { coronary vessels }(\%)\end{array}$} & None & 11313 & 83.08 \\
\hline & One & 1137 & 8.35 \\
\hline & Two & 618 & 4.54 \\
\hline & Three & 373 & 2.74 \\
\hline & Four or greater & 176 & 1.29 \\
\hline Left main disease $(\%)$ & & 323 & 2.37 \\
\hline
\end{tabular}

TABLE 1. Continued

\begin{tabular}{|c|c|c|c|}
\hline Variable & Level & $\mathbf{N}$ & $\begin{array}{c}\text { Overal } \\
(\%)\end{array}$ \\
\hline Aortic stenosis $(\%)$ & & 1982 & 14.56 \\
\hline Mitral stenosis $(\%)$ & & 831 & 6.10 \\
\hline Tricuspid stenosis (\%) & & 88 & 0.65 \\
\hline Pulmonic stenosis (\%) & & 30 & 0.22 \\
\hline $\begin{array}{l}\text { Aortic insufficiency } \\
\quad \text { (moderate to severe) }(\%)\end{array}$ & & 5535 & 40.65 \\
\hline $\begin{array}{l}\text { Mitral insufficiency } \\
\quad \text { (moderate to severe) }(\%)\end{array}$ & & 7377 & 54.17 \\
\hline $\begin{array}{l}\text { Tricuspid insufficiency } \\
\quad \text { (moderate to severe) }(\%)\end{array}$ & & 2220 & 16.30 \\
\hline $\begin{array}{l}\text { Pulmonic insufficiency } \\
\text { (moderate to severe) }(\%)\end{array}$ & & 344 & 2.53 \\
\hline
\end{tabular}

bioprosthetic valve replacement was the most commonly performed operation, comprising $60.6 \%$ of total aortic valve procedures and $42.17 \%$ of total mitral valve procedures. Mechanical valves were used in $31.8 \%$ of aortic valve operations, $27.16 \%$ of mitral valve operations, and $4.1 \%$ of tricuspid operations. The mitral valve had the highest rate of repair $(24.6 \%)$, followed by the tricuspid valve $(11.78 \%)$ and aortic valve $(0.22 \%)$. Overall, valve repair was a minority of the procedures performed. The Ross procedure was rare, with only 5 reported cases in the database.

Operative mortality was $8.2 \%$. Operative mortality by valve type was $6.02 \%$ for isolated aortic valve procedures, $7.89 \%$ for isolated mitral valve procedures, and $6.07 \%$ for isolated tricuspid valve procedures. Multiple valve surgery carried the highest risk of operative mortality at $13.2 \%$. Postoperative complications were reported in $53 \%$ of patients. Median postoperative length of stay was 8 days. In patients who had a major postoperative complication, the mean postoperative length of stay was significantly longer than in those without a major complication (18 days vs 9 days) $(P<.0001)$. Reoperation for any reason was required in $15 \%$ of patients. Within this subgroup, $6.2 \%$ required reoperation for bleeding with a very small number requiring reoperation for valvular dysfunction $(0.5 \%)$. The rate of deep sternal wound infection was low $(0.5 \%)$. Prolonged ventilation ( $>24$ hours) $(27.9 \%)$ was the most commonly reported complication, followed by atrial fibrillation $(19.5 \%)$. Despite a relatively high rate of preoperative cerebrovascular disease $(23.3 \% ; \mathrm{n}=3176)$, of which the majority $(81 \% ; n=2580)$ were strokes, the rate of new postoperative neurologic complications was low. Any neurologic complication occurred in $4.4 \%$ of patients, of which $2.6 \%$ were classified as stroke. Transient neurologic deficit was documented in $0.95 \%$, and continuous coma was present in $1.18 \%$. When examining stroke rate in patients with a documented preoperative stroke $(n=2580)$, we found that 
TABLE 2. Operative statistics and outcomes

\begin{tabular}{|c|c|c|c|}
\hline Variable & Level & $N=13,617$ & $\begin{array}{c}\text { Overall } \\
(\%)\end{array}$ \\
\hline \multirow[t]{4}{*}{ Status of the procedure $(\%)$} & Elective & 5848 & 42.95 \\
\hline & Urgent & 6778 & 49.78 \\
\hline & Emergency & 924 & 6.79 \\
\hline & Emergency salvage & 67 & 0.49 \\
\hline $\begin{array}{l}\text { Coronary artery bypass } \\
\text { grafting }(\%)\end{array}$ & & 2304 & 16.92 \\
\hline \multirow[t]{7}{*}{ Aortic valve procedure $(\%)$} & Total & 4866 & 35.73 \\
\hline & Mechanical valve & 1546 & 31.77 \\
\hline & Biologic valve & 2952 & 60.66 \\
\hline & Homograft & 256 & 5.26 \\
\hline & Missing & 96 & 1.97 \\
\hline & Ross procedure & 5 & 0.10 \\
\hline & Repair & 11 & 0.22 \\
\hline \multirow[t]{7}{*}{ Mitral valve procedure ( $\%)$} & Total & 5478 & 40.23 \\
\hline & Mechanical valve & 1488 & 27.16 \\
\hline & Biologic valve & 2310 & 42.16 \\
\hline & Homograft & 8 & 0.15 \\
\hline & Missing & 318 & 5.80 \\
\hline & Autograft & 6 & 0.11 \\
\hline & Repair & 1348 & 24.60 \\
\hline \multirow[t]{7}{*}{ Tricuspid valve procedure $(\%)$} & Total & 560 & 4.11 \\
\hline & Mechanical valve & 23 & 4.10 \\
\hline & Biologic valve & 307 & 54.82 \\
\hline & Homograft & 1 & 0.17 \\
\hline & Missing & 160 & 28.57 \\
\hline & Autograft & 3 & 0.53 \\
\hline & Repair & 66 & 11.78 \\
\hline $\begin{array}{l}\text { Multiple valve } \\
\text { procedure (\%) }\end{array}$ & & 2713 & 19.92 \\
\hline $\begin{array}{l}\text { Any postoperative } \\
\text { complication }(\%)\end{array}$ & & 7236 & 53.14 \\
\hline $\begin{array}{l}\text { Reoperation for any } \\
\quad \text { reason }(\%)\end{array}$ & & 2042 & 15.00 \\
\hline $\begin{array}{l}\text { Reoperation for } \\
\text { bleeding (\%) }\end{array}$ & & 838 & 6.15 \\
\hline $\begin{array}{l}\text { Reoperation for valvular } \\
\text { dysfunction }(\%)\end{array}$ & & 67 & 0.49 \\
\hline $\begin{array}{l}\text { Reoperation for graft } \\
\text { occlusion }(\%)\end{array}$ & & 6 & 0.04 \\
\hline $\begin{array}{l}\text { Reoperation for other } \\
\text { cardiac problem }(\%)\end{array}$ & & 463 & 3.40 \\
\hline $\begin{array}{l}\text { Reoperation for other } \\
\text { noncardiac problem }(\%)\end{array}$ & & 949 & 6.97 \\
\hline $\begin{array}{l}\text { Perioperative myocardial } \\
\text { infarction }(\%)\end{array}$ & & 168 & 1.23 \\
\hline Any infection $(\%)$ & & 759 & 5.57 \\
\hline Mediastinitis (\%) & & 67 & 0.49 \\
\hline Sepsis $(\%)$ & & 586 & 4.30 \\
\hline Any neurologic complication $(\%)$ & & 599 & 4.40 \\
\hline Postoperative stroke $>72 \mathrm{~h}(\%)$ & & 357 & 2.62 \\
\hline Transient neurologic deficit (\%) & & 130 & 0.95 \\
\hline Continuous coma $>24 \mathrm{~h}(\%)$ & & 161 & 1.18 \\
\hline Any pulmonary complication $(\%)$ & & 3592 & 26.38 \\
\hline
\end{tabular}

TABLE 2. Continued

\begin{tabular}{|c|c|c|c|}
\hline Variable & Level & $N=13,617$ & $\begin{array}{c}\text { Overall } \\
(\%) \\
\end{array}$ \\
\hline Prolonged ventilation $(\%)$ & & 3809 & 27.97 \\
\hline Pulmonary embolism (\%) & & 36 & 0.26 \\
\hline Pneumonia (\%) & & 771 & 5.66 \\
\hline Renal failure (\%) & & 803 & 5.90 \\
\hline Postoperative dialysis (\%) & & 548 & 4.02 \\
\hline Any vascular complication (\%) & & 128 & 0.94 \\
\hline Acute limb ischemia (\%) & & 117 & 0.86 \\
\hline Heart block (\%) & & 846 & 6.21 \\
\hline $\begin{array}{l}\text { Anticoagulant } \\
\text { complication (\%) }\end{array}$ & & 432 & 3.17 \\
\hline Cardiac arrest $(\%)$ & & 518 & 3.80 \\
\hline Tamponade $(\%)$ & & 155 & 1.14 \\
\hline $\begin{array}{l}\text { Gastrointestinal } \\
\text { complication }(\%)\end{array}$ & & 742 & 5.45 \\
\hline Multisystem organ failure (\%) & & 440 & 3.23 \\
\hline Atrial fibrillation $(\%)$ & & 2644 & 19.42 \\
\hline Other complication (\%) & & 1199 & 8.81 \\
\hline \multirow[t]{4}{*}{ Total length of stay (d) } & Median & 13575 & 14.00 \\
\hline & 25 th & & 8.00 \\
\hline & 75 th & & 24.00 \\
\hline & Mean & & 18.90 \\
\hline \multirow{4}{*}{$\begin{array}{l}\text { Postoperative length } \\
\text { of stay (d) }\end{array}$} & Median & 13576 & 8.00 \\
\hline & 25 th & & 6.00 \\
\hline & 75 th & & 14.00 \\
\hline & Mean & & 12.64 \\
\hline \multicolumn{4}{|l|}{ Preoperative length of stay (d) } \\
\hline Recent stroke ( $<2$ wk) & Median & 759 & 7.00 \\
\hline Remote stroke (>2 wk) & Median & 1729 & 5.00 \\
\hline \multicolumn{4}{|l|}{$\begin{array}{l}\text { Postoperative length } \\
\text { of stay (d) }\end{array}$} \\
\hline Recent stroke ( $<2$ wk) & Median & 755 & 11.00 \\
\hline Remote stroke (>2 wk) & Median & 1725 & 9.00 \\
\hline In-hospital mortality (\%) & & 1046 & 7.68 \\
\hline \multicolumn{4}{|l|}{ Operative mortality } \\
\hline Overall (\%) & & 1117 & 8.20 \\
\hline $\begin{array}{l}\text { Isolated aortic valve } \\
\text { procedures }(\mathrm{n}=4866)\end{array}$ & & 293 & 6.02 \\
\hline $\begin{array}{l}\text { Isolated mitral valve } \\
\text { procedures }(\mathrm{n}=5478)\end{array}$ & & 432 & 7.89 \\
\hline $\begin{array}{l}\text { Isolated tricuspid valve } \\
\text { procedures }(\mathrm{n}=560)\end{array}$ & & 34 & 6.07 \\
\hline $\begin{array}{l}\text { Multiple valve procedures } \\
\quad(\mathrm{n}=2713)\end{array}$ & & 358 & 13.20 \\
\hline
\end{tabular}

the rate of postoperative stroke was similarly low at $4.34 \%$ $(\mathrm{n}=112)$. In those patients with preoperative stroke, the median preoperative length of stay was 7 days compared with 5 days in those without preoperative stroke. The postoperative length of stay was longer (11 days) in patients with a recent stroke (within 2 weeks of operation) than in those with a remote stroke (9 days).

The results of the simplified model predicting the composite end point of major morbidity or mortality are listed 
in Table 3. This model consists of the 14 variables that explained more than $93 \%$ of the variation in the full logistic regression (Table E1). According to their predictive value, each variable was assigned a corresponding point score, also listed in Table 3. The most important predictor of the composite end point of death or major complication was an operation classified as emergency, emergency/salvage, or cardiogenic shock. The second most important predictive value was renal failure or a preoperative creatinine level greater than $2.0 \mathrm{mg} / \mathrm{dL}$. The points assigned to the remaining variables are also listed in Table 3. The relationship between the observed composite end point of major morbidity or mortality and that predicted by this model in the test group of patients is illustrated graphically in Figure 1, $A$. The model demonstrated good predictive ability compared with observed mortality with a C statistic of 0.72870 .

Logistic regression analysis also was performed for the predictors of the sole end point of operative mortality (Table E2). The results of this simplified model are demonstrated in Table 4. As with the composite end point, the model consisted of the 13 most important variables that explained more than $93 \%$ of the variation in the full logistic regression model (Table E2). An operation classified as emergency, emergency/salvage, or cardiogenic shock was the most powerful predictor of operative mortality, with the second most important predictor renal failure or a preoperative creatinine level greater than $2.0 \mathrm{mg} / \mathrm{dL}$. The next most important predictors of mortality were active (vs treated) endocarditis and the use of preoperative inotropic therapy and/or an intra-aortic balloon pump. Several variables were predictive in the composite end point model but did not reach significance in the predictive model for operative mortality alone. Age greater than 60 years, body surface area greater than 1.9, female gender, and New York Heart Association class IV heart failure were all predictors in the composite model but did not prove significant as the
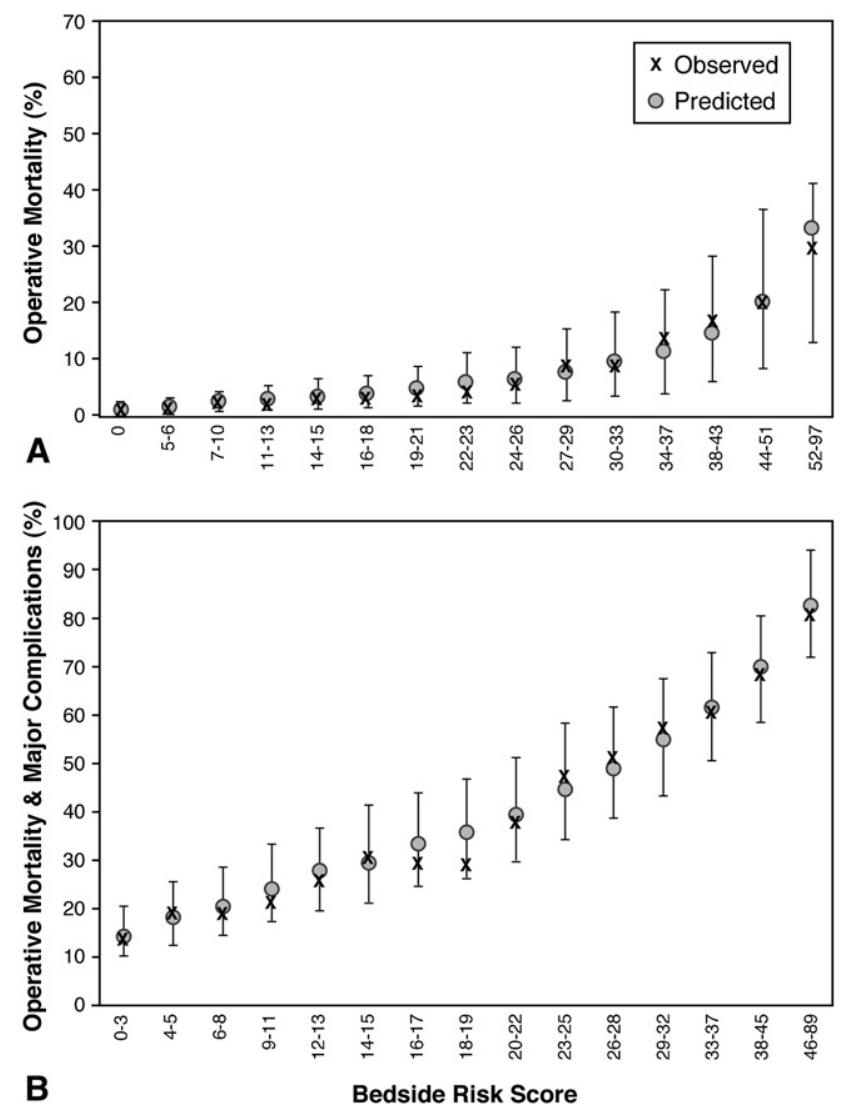

FIGURE 1. A, Observed versus expected mortality after surgery for endocarditis based on bedside risk score. B, Observed versus expected major morbidity and mortality after surgery for endocarditis based on beside risk score.

predictor of operative mortality alone. These variables were replaced in the mortality-alone model by chronic lung disease, non-insulin-dependent diabetes, and hypertension. However, the most powerful predictors of both operative

TABLE 3. Simplified model and point estimate for the composite end point of major morbidity and mortality

\begin{tabular}{|c|c|c|c|c|c|}
\hline Parameter & Standard estimate & Probability & OR & CI & Points \\
\hline Female gender & 0.30923 & $<.0001$ & 1.36237 & $(1.35,1.38)$ & 5 \\
\hline $\mathrm{BSA}>1.9$ & 0.09389 & $<.0001$ & 1.09844 & $(1.09,1.11)$ & 1 \\
\hline Age $>60$ & 0.26839 & $<.0001$ & 1.30786 & $(1.30,1.32)$ & 4 \\
\hline Prior CABG & 0.32403 & $<.0001$ & 1.38269 & $(1.37,1.40)$ & 5 \\
\hline Status: urgent or emergency, no cardiogenic shock & 0.40854 & $<.0001$ & 1.50461 & $(1.49,1.52)$ & 6 \\
\hline Status: emergency, salvage, or cardiogenic shock & 1.13463 & $<.0001$ & 3.11004 & $(3.04,3.18)$ & 17 \\
\hline Preoperative IABP or inotropes & 0.83191 & $<.0001$ & 2.29770 & $(2.26,2.34)$ & 12 \\
\hline Multiple valve procedure & 0.45954 & $<.0001$ & 1.58334 & $(1.57,1.60)$ & 7 \\
\hline Prior valve surgery & 0.32296 & $<.0001$ & 1.38121 & $(1.37,1.40)$ & 5 \\
\hline IDDM & 0.48610 & $<.0001$ & 1.62597 & $(1.60,1.65)$ & 7 \\
\hline NYHA class IV & 0.38932 & $<.0001$ & 1.47598 & $(1.46,1.49)$ & 6 \\
\hline Active endocarditis & 0.45781 & $<.0001$ & 1.58061 & $(1.57,1.60)$ & 7 \\
\hline Renal failure or $\mathrm{Cr}>2.0$ & 0.77041 & $<.0001$ & 2.16064 & $(2.14,2.18)$ & 12 \\
\hline Arrhythmia & 0.31833 & $<.0001$ & 1.37484 & $(1.36,1.39)$ & 5 \\
\hline
\end{tabular}

C statistic $=0.72870 . O R$, Odds ratio; $C I$, confidence interval; $B S A$, body surface area; $C A B G$, coronary artery bypass grafting; IABP, intra-aortic balloon pumping; $I D D M$, insulin-dependent diabetes mellitus; NYHA, New York Heart Association; $\mathrm{Cr}$, creatinine. 
TABLE 4. Simplified model and point estimate for postoperative mortality

\begin{tabular}{|c|c|c|c|c|c|}
\hline Parameter & Standard estimate & Probability & OR & CI & Points \\
\hline Prior CABG & 0.48958 & $<.0001$ & 1.63163 & $(1.60,1.67)$ & 7 \\
\hline Status: urgent or emergency, no cardiogenic shock & 0.42207 & $<.0001$ & 1.52511 & $(1.50,1.55)$ & 6 \\
\hline Status: emergency, salvage, or cardiogenic shock & 1.15279 & $<.0001$ & 3.167 & $(3.03,3.31)$ & 17 \\
\hline Preoperative IABP or Inotropes & 0.67227 & $<.0001$ & 1.95869 & $(1.89,2.03)$ & 10 \\
\hline Multiple valve procedure & 0.602 & $<.0001$ & 1.82577 & $(1.79,1.86)$ & 9 \\
\hline Prior valve surgery & 0.47119 & $<.0001$ & 1.6019 & $(1.57,1.64)$ & 7 \\
\hline IDDM & 0.54652 & $<.0001$ & 1.72723 & $(1.68,1.78)$ & 8 \\
\hline NIDDM & 0.43098 & $<.0001$ & 1.53877 & $(1.50,1.58)$ & 6 \\
\hline Hypertension & 0.342 & $<.0001$ & 1.40776 & $(1.38,1.43)$ & 5 \\
\hline Chronic lung disease & 0.34443 & $<.0001$ & 1.41119 & $(1.38,1.44)$ & 5 \\
\hline Active endocarditis & 0.69541 & $<.0001$ & 2.00453 & $(1.97,2.04)$ & 10 \\
\hline Renal failure or $\mathrm{Cr}>2.0$ & 0.82723 & $<.0001$ & 2.28698 & $(2.24,2.33)$ & 12 \\
\hline Arrhythmia & 0.5043 & $<.0001$ & 1.65582 & $(1.62,1.69)$ & 8 \\
\hline
\end{tabular}

C statistic $=0.75784 . O R$, Odds ratio; $C I$, confidence interval; $C A B G$, coronary artery bypass grafting; IABP, intra-aortic balloon pump; IDDM, insulin-dependent diabetes mellitus; NIDDM, non-insulin-dependent diabetes mellitus; $\mathrm{Cr}$, creatinine.

mortality and the composite end point of major morbidity remained similar. This model also demonstrated good predictive ability compared with observed mortality with a $\mathrm{C}$ statistic of 0.75784 . In both models, "any valve repaired" (compared with replacement) was associated with improved survival and decreased morbidity (Tables E1 and E2). This effect was largely due to repair of the mitral valve $(9.91 \%)$ inasmuch as the rates of repair for tricuspid $(0.48 \%)$ and aortic valves $(0.08 \%)$ were low.

\section{DISCUSSION}

The patient with IE often presents a challenging clinical dilemma. In the critically ill patient, surgical therapy for IE can be lifesaving. Despite the evidence that the incidence of IE is increasing with time, however, few data are available to guide surgical decision-making. The purpose of this study was to develop a simplified risk score model that could aid in clinical decisions in the patient with IE. According to this information, a patient with a preoperative score of 35 points on both models would be expected to have an operative risk of at least $10 \%$ mortality and $60 \%$ combined major morbidity and mortality. The overall mortality in this series was $8.2 \%$. This mortality is significantly lower than the reported mortality for dialysis patients undergoing surgery for IE $(24.4 \%)$ and the reported in-hospital mortality for all patients with IE $(>20 \%)^{2,3,6}$ Although the morbidity in this series was high relative to other categories, surgical therapy remains very effective in the treatment of patients with IE.

The preoperative hemodynamic condition of the patient was the greatest predictor of mortality and major morbidity after surgery for IE. Those patients in the emergency, salvage, or cardiogenic shock classes clearly had worse outcomes after surgery than those who were not in these classes. This finding is consistent with other risk models of cardiac surgery, specifically those in coronary artery bypass grafting as well as valvular heart disease. ${ }^{12}$ The im- portance of this model, however, is that it can assign a relative weight to the other preoperative variables through the development of the scoring system, as shown in Tables 3 and 4 . Using this point scoring system, a clinician can develop a preoperative bedside risk profile that can greatly facilitate the decision-making process in often difficult clinical scenarios. Even among patients with the highest point scores, the actual and predicted operative mortality did not exceed $30 \%$, suggesting that future patient selection should be fairly liberal, although exact selection criteria used in the included patients cannot be documented.

In the model, preoperative cerebrovascular disease was not a significant predictor of operative morbidity or mortality. In addition, the rate of postoperative cerebrovascular complications was low at $4.4 \%$, of which $2.6 \%$ were classified as stroke. Preoperative cerebrovascular disease has been identified as a risk factor for in-hospital mortality from cardiac valve surgery. ${ }^{12,13}$ However, it was not identified as a risk factor for in-hospital mortality in patients with dialysis-dependent renal failure who underwent surgery for IE. ${ }^{6}$ Similarly, the results of this analysis suggest that preoperative cerebrovascular disease is not a risk factor for postoperative complications in patients with IE. Even among patients with a recent preoperative stroke, the rate of postoperative stroke was low $(4.3 \%)$ with a median of only 7 days between hospital admission and operation. These data suggest that the recommended practice of delaying surgery after a recent stroke from IE before proceeding with cardiac surgery may need re-examination. ${ }^{14}$

One finding of concern in this study was that riskadjusted surgical mortality has remained relatively stable over the period of the study. IE, however, is a constantly changing disease. The rapid increase in staphylococcal infections and an increase in cardiac device implantations make it difficult to compare surgical results from year to year. ${ }^{15}$ The finding that those patients classified as having "active" endocarditis contributed significantly to the 
surgical risk identifies this as one area for possible improvement. However, converting patients from "active" to "treated" status must be counterbalanced against the risk of postponing surgery to complete antibiotic therapy. Indeed, postponing surgery may increase the risks of intervening complications of IE, such as embolization, heart failure, and death.

Converting the patient to treated status could also facilitate another candidate for possible quality improvement: valve repair. This has been identified as an area of improvement in other series of surgical IE patients, particularly related to the mitral valve. ${ }^{16,17}$ Indeed, in this study "any valve repair" also was predictive of better outcomes in this study. More patients converted to treated status may facilitate higher rates of valve repair. ${ }^{17}$ This approach however, must be individualized to the clinical scenario. In some cases, early surgery of active IE may allow more patients to undergo repair, inasmuch as further valvular destruction is avoided. Although the short-term results of valve repair in IE are promising, the long-term outcomes in IE are not known at this time. ${ }^{17}$

Although patients with treated IE who underwent valve repair had better outcomes in this study, a strong selection bias probably exists in these results. That is, patients with a more indolent form of IE were more likely to tolerate a period of antibiotic therapy and subsequently be candidates for valve repair. Nevertheless, $43 \%$ of all surgical procedures performed in the study were classified as elective, demonstrating that large numbers of patients could possibly tolerate an antibiotic regimen and subsequent repair. The rates of valve repair in this study, however, remain relatively low. Mitral valve repair represented only $24.6 \%$ of all mitral valve procedures performed. The rate of mitral valve repair in this database analysis is lower than published reports from single centers, suggesting that increasing the rate of mitral valve repair is indeed possible and may improve outcomes. ${ }^{3,17,18}$ Indeed, with the development of new valve repair techniques, such as the use of autologous pericardium and artificial chordal replacement, it may be possible to increase the rate of valve repair to include the tricuspid and aortic valves. ${ }^{19-21}$

The limitations of this study reflect the limitations of a retrospectively collected database. The STS ACSD data supplied for this analysis consisted of data submitted voluntarily from 824 participating centers in North America. In addition, the STS ACSD does not provide outcomes beyond the 30-day perioperative period, and long-term follow-up is not available. However, operative mortality is a significant variable in IE, and the study does represent the largest series of the surgical treatment of IE to date in the literature. An important undefined potential confounding variable in the data set is etiologic organism. The current STS data submission form does not provide microbiologic information. The type of microorganism involved in IE may have a significant effect on surgical outcomes, but it is not captured in this analysis. Management principles may change, depending on the etiologic organism, especially with infections involving resistant staphylococci and fungi. One additional, and key, limitation is that this series includes both native valve endocarditis and prosthetic valve endocarditis, inasmuch as the current STS data set does not distinguish between the two. These deficiencies are being corrected in future data sets. The inclusion of tricuspid valve endocarditis is this analysis is another possible confounding variable. Although patients with tricuspid valve disease make up a minority of the study population, right-sided and left-sided IE may represent different disease entities. Future studies will be aided by refinements to the database, allowing us to study more homogeneous patient populations.

In summary, the surgical patient with IE remains a significant clinical challenge. Data from this analysis confirms that surgery is a very effective tool in the management of these complex patients. Even with relatively high risk "scores," mortality rates are less than $10 \%$. Surgical morbidity and mortality depend on variety of preoperative factors, most important, the preoperative hemodynamic status of the patient. The risk scoring system presented here informs patient selection, provides risk stratification, and allows communication with patients and other physicians.

\section{References}

1. Bashore TM, Cabell C, Fowler V Jr. Update on infective endocarditis. Curr Probl Cardiol. 2006;31:274-352

2. Murdoch DR, Corey GR, Hoen B, Miro JM, Fowler VG Jr, Bayer AS, et al. Clinical presentation, etiology, and outcome of infective endocarditis in the 21 st century: the International Collaboration on Endocarditis-Prospective Cohort Study. Arch Intern Med. 2009;169:463-73.

3. Shang E, Forrest GN, Chizmar T, Chim J, Brown JM, Zhan M, et al. Mitral valve infective endocarditis: benefit of early operation and aggressive use of repair. Ann Thorac Surg. 2009;87:1728-34.

4. Miro JM, Anguera I, Cabell CH, Chen AY, Stafford JA, Corey GR, et al. Staphylococcus aureus native valve infective endocarditis: report of 566 episodes from the International Collaboration on Endocarditis Merged Database. Clin Infect Dis. 2005;41:507-14.

5. Vikram HR, Buenconsejo J, Hasbun R, Quagliarello VJ. Impact of valve surgery on 6-month mortality in adults with complicated, left-sided native valve endocarditis: a propensity analysis. JAMA. 2003;290:3207-14.

6. Rankin JS, Milford-Beland S, O'Brien SM, Edwards FH, Peterson ED, Glower DD, et al. The risk of valve surgery for endocarditis in patients with dialysis-dependent renal failure. J Heart Valve Dis. 2007;16:617-22.

7. Aksoy O, Sexton DJ, Wang A, Pappas PA, Kourany W, Chu V, et al. Early surgery in patients with infective endocarditis: a propensity score analysis. Clin Infect Dis. 2007;44:364-72.

8. Durack DT. Evaluating and optimizing outcomes of surgery for endocarditis. JAMA. 2003;290:3250-1.

9. Tleyjeh IM, Kashour T, Zimmerman V, Steckelberg JM, Wilson WR, Baddour LM. The role of valve surgery in infective endocarditis management: a systematic review of observational studies that included propensity score analysis. Am Heart J. 2008;156:901-9.

10. Gammie JS, Sheng S, Griffith BP, Peterson ED, Rankin JS, O'Brien SM, et al. Trends in mitral valve surgery in the United States: results from the Society of Thoracic Surgeons Adult Cardiac Surgery Database. Ann Thorac Surg. 2009;87: 1431-7.

11. Dokholyan RS, Muhlbaier LH, Falletta JM, Jacobs JP, Shahian D, Haan CK, et al. Regulatory and ethical considerations for linking clinical and administrative databases. Am Heart J. 2009;157:971-82. 
12. Hannan EL, Wu C, Bennett EV, Carlson RE, Culliford AT, Gold JP, et al. Risk index for predicting in-hospital mortality for cardiac valve surgery. Ann Thorac Surg. 2007;83:921-9.

13. Rankin JS, Hammill BG, Ferguson TB Jr, Glower DD, O’Brien SM, DeLong ER, et al. Determinants of operative mortality in valvular heart surgery. J Thorac Cardiovasc Surg. 2006;131:547-57.

14. Gillinov AM, Shah RV, Curtis WE, Stuart RS, Cameron DE, Baumgartner WA, et al. Valve replacement in patients with endocarditis and acute neurologic deficit. Ann Thorac Surg. 2005;61:1125-9.

15. Cabell CH, Jollis JG, Peterson GE, Corey GR, Anderson DJ, Sexton DJ, et al. Changing patient characteristics and the effect on mortality in endocarditis. Arch Intern Med. 2002;162:90-4

16. Ruttmann E, Legit C, Poelzl G, Mueller S, Chevtchik O, Cottogni M, et al. Mitral valve repair provides improved outcome over replacement in active infective endocarditis. J Thorac Cardiovasc Surg. 2005;130:765-71.

17. Gammie JS, O'Brien SM, Griffith BP, Peterson ED. Surgical treatment of mitral valve endocarditis in North America. Ann Thorac Surg. 2005;80:2199-204.

18. Mihaljevic T, Paul S, Leacche M, Rawn JD, Aranki S, O'Gara PT, et al. Tailored surgical therapy for acute native mitral valve endocarditis. $J$ Heart Valve Dis. 2004; 13:210-6.

19. Ng CK, Nesser J, Punzengruber C, Pachinger O, Auer J, Franke H, et al. Valvuloplasty with glutaraldehyde-treated autologous pericardium in patients with complex mitral valve pathology. Ann Thorac Surg. 2001;71:78-85.

20. Rankin JS, Orozco RE, Rodgers TL, Alfery DD, Glower DD. "Adjustable" artificial chordal replacement for repair of mitral valve prolapse. Ann Thorac Surg. 2006;81:1526-8.

21. Aicher D, Fries R, Rodionycheva S, Schmidt K, Langer F, Schafers HJ. Aortic valve repair leads to a low incidence of valve-related complications. Eur J Cardiothorac Surg. 2010;37:127-32.

\section{Discussion}

Dr James M. Douglas (Bellingham, Wash). I congratulate the authors on their monumental undertaking to develop a comprehensible risk assessment system for the evaluation of the very diverse and often exceedingly high-risk population of patients undergoing surgical treatment of endocarditis. In this paper the authors have convincingly demonstrated the importance of a number of preoperative risk factors in this patient cohort that I am certain we would all agree are legitimate. However, I am equally intrigued by the number of questions that may be stimulated by examining this large data set. To adhere to the time constraints, I will limit these thoughts to just a few.

Ever since Will C. Sealy at Duke proved the improbable by successfully performing valve replacement in the patient with active endocarditis, surgeons have relied on a set of surgical indications that include congestive heart failure, persistent infection, paravalvular extension, valvular dysfunction, and recurrent emboli. In essence, surgery has generally been performed in patients in whom medical therapy has failed. Unfortunately, many of the highest risk patients will also die with surgery. Although the scoring system will confirm what we already know, that is, that the patient is at high risk, my first question is, can you tell us which patient will likely die? More specifically, were you able to identify any patient subgroup for which surgical intervention would be unwise?

My second question is along a similar line. The most important risk factors for morbidity and mortality that you identified were primarily functional or physiologic. Using these criteria, you stated in the paper that the subgroup of patients with the highest risk scores had operative mortalities that did not exceed $30 \%$. However, the most vexing patients with endocarditis are those with serious anatomic challenges, including pseudoaneurysms, fistulas, and extensive paravalvular abscesses, especially in the setting of prosthetic valve endocarditis. Do you believe that the physiologic parameters trump these anatomic considerations or would inclusion of these factors in a database better help us to stratify these patients?

Last, one of your coauthors, Dr Gammie, has previously mined a database and provided strong support for the use of mitral valve repair in the treatment of endocarditis. This study likewise attests to the potential superiority of this approach when feasible. Despite these data, surgeons may still question the superiority of the technique itself versus patient selection bias in this heterogeneous population. What are your thoughts on this topic and how do you suggest we resolve with persistent issue?

Dr Gaca. Who will die? I think that is very interesting. Even with the highest risk score, our mortality rates, as you correctly pointed out, did not exceed $30 \%$, so that means every one in this room is already making these decisions on who will die and who will not die. That is really a limitation of the database. Only the people who get surgery are in the database, and I think that we are doing a very good job. I think we can do better, but that is the eternal question. That goes into your other question, the limitations of the database. Yes, there are anatomic factors and, no, they are not included in the database. The big limitation to this database is that we do not have microbiology data, and one of the limitations is that we lumped prosthetic valve endocarditis in with native valve endocarditis. I think that in future data sets we are going to include the microbiology in the STS database and we are going to try to look at prosthetic endocarditis alone, because that as you probably can imagine is a different animal. This speaks to the importance of doing these database papers, because they examine our own clinical practice and allow us to refine further data sets to answer the questions that you have raised.

As for mitral repair, you are right. One of our authors has been a steadfast proponent of mitral valve repair, and indeed mitral valve repair in this study has actually shown an improved survival. Obviously not everyone can undergo repair, and are they having valve repair because their disease is more indolent? That is possible. Do you we have long-term data? No. I think the next study we need to do is to link this kind of data to Centers for Medicare and Medicaid Services data to see what the long-term survival is of these patients. That is really the next step beyond these STS data base papers.

Dr Anthony Furnary (Portland, Ore). Jeff, you said-I am just going to read from your abstract- "Interestingly, risk-adjusted mortality is not improved in recent years, with operative mortality for 2008 having increased relative to previous years." Did you present that information?

Dr Gaca. That is in the paper. We did not present it, but it is true. Operative mortality from this disease is not getting better, and I think that has a lot to do with the fact that endocarditis is a changing disease. There are a lot more devices being put in people. There is a rise in staphylococcal infections, so the endocarditis of 5 to 10 years ago is not the same endocarditis that we see this year.

Dr Furnary. Is the risk-adjusted mortality, O/E ratio, getting worse?

Dr Gaca. It is not improving.

Dr Furnary. It is not getting better.

Dr Gaca. Yes, it is stagnant. 
Dr Furnary. You have one risk algorithm or two risk algorithms for all valve disease. Would there be a better agreement or area under the raw curve if you segregated out mitral versus aortic versus tricuspid?

Dr Gaca. Yes, I think so, mainly because people were able to repair more of the mitral valves. I think the curves for the aortic and tricuspid valves will be diferent.

Dr Furnary. That is something you would consider?

Dr Gaca. Yes.

Dr Jack Copeland (Tucson, Ariz). Many databases in the past years have shown a history of smoking as a very powerful predictor of bad outcome. We have seen it in transplantation and in bridge to transplantation. Yesterday it was presented as a predictor of bad outcome in lung surgery. Did you include this as part of your analysis and was it predictive of bad outcome?

Dr Gaca. That is a good question. Smoking was included. It is in the full model and it was not predictive, but, yes, it is in the model.

Speaker. Jeff, when you publish your paper in the Journal, would you be so kind as to publish both the beta coefficients and the intercept so that we can use these clinically in our centers, and would you consider publishing separate information for mitral, aortic, and tricuspid?

Dr Gaca. Yes, that information is available. It will be in the on-line tables owing to the constraints of the Journal, but we will publish that information. 
TABLE E1. Full logistic regression model and point estimate for composite end point of major morbidity and mortality

\begin{tabular}{|c|c|c|c|c|}
\hline Parameter & Estimate & $P$ value & Odds ratio & $95 \% \mathrm{CI}$ \\
\hline \multicolumn{5}{|l|}{ Year of surgery } \\
\hline 2008 & -0.2267 & .1439 & 0.797 & $(0.59,1.08)$ \\
\hline 2007 & -0.4140 & .0034 & 0.661 & $(0.5,0.87)$ \\
\hline 2006 & -0.3723 & .0079 & 0.689 & $(0.52,0.91)$ \\
\hline 2005 & -0.3388 & .0214 & 0.713 & $(0.53,0.95)$ \\
\hline 2004 & -0.1622 & .2371 & 0.85 & $(0.65,1.11)$ \\
\hline 2003 & -0.0745 & .6212 & 0.928 & $(0.69,1.25)$ \\
\hline 2002 (reference) & 0.0000 & & 1 & $(1,1)$ \\
\hline Female gender & 0.4776 & $<.0001$ & 1.612 & $(1.38,1.89)$ \\
\hline Body surface area & 0.2144 & .2070 & 1.239 & $(0.89,1.73)$ \\
\hline Age & 0.0275 & $<.0001$ & 1.028 & $(1.02,1.03)$ \\
\hline Dialysis & 1.2246 & $<.0001$ & 3.403 & $(2.55,4.54)$ \\
\hline Renal failure/creatinine $>2$ without dialysis & 0.6545 & $<.0001$ & 1.924 & $(1.59,2.33)$ \\
\hline Normal creatinine (reference) & 0.0000 & & 1 & $(1,1)$ \\
\hline Urgent or emergency status without shock & 0.3700 & $<.0001$ & 1.448 & $(1.22,1.72)$ \\
\hline Emergency, salvage, or cardiogenic shock & 1.0594 & $<.0001$ & 2.885 & $(2.18,3.81)$ \\
\hline Congestive heart failure & 0.0225 & .7646 & 1.023 & $(0.88,1.19)$ \\
\hline Active endocarditis & 0.7332 & $<.0001$ & 2.082 & $(1.76,2.46)$ \\
\hline Preoperative inotropes or IABP & 0.5317 & $<.0001$ & 1.702 & $(1.38,2.1)$ \\
\hline One distal coronary anastomosis & 0.1799 & .0846 & 1.197 & $(0.98,1.47)$ \\
\hline Two distal coronary anastomoses & 0.3234 & .0208 & 1.382 & $(1.05,1.82)$ \\
\hline Three distal coronary anastomoses & 0.2683 & .1319 & 1.308 & $(0.92,1.85)$ \\
\hline Four or more distal coronary anastomoses & 0.6134 & .0102 & 1.847 & $(1.16,2.95)$ \\
\hline Multiple valve surgery & 0.8274 & $<.0001$ & 2.287 & $(1.88,2.78)$ \\
\hline Tricuspid valve surgery & 0.4257 & .0218 & 1.531 & $(1.06,2.2)$ \\
\hline Mitral valve surgery & 0.2420 & .0027 & 1.274 & $(1.09,1.49)$ \\
\hline Aortic valve surgery (reference) & 0.0000 & & 1 & $(1,1)$ \\
\hline Prior $\mathrm{CABG}$ & 0.2010 & .0717 & 1.223 & $(0.98,1.52)$ \\
\hline Prior valve surgery & 0.4156 & $<.0001$ & 1.515 & $(1.28,1.79)$ \\
\hline IDDM & 0.3728 & .0002 & 1.452 & $(1.19,1.77)$ \\
\hline NIDDM & 0.2984 & .0008 & 1.348 & $(1.13,1.6)$ \\
\hline NYHA class IV & 0.1773 & .0351 & 1.194 & $(1.01,1.41)$ \\
\hline African American race & 0.0723 & .4488 & 1.075 & $(0.89,1.3)$ \\
\hline Preoperative steroid administration & 0.1399 & .2740 & 1.15 & $(0.9,1.48)$ \\
\hline Hypertension & 0.1024 & .1881 & 1.108 & $(0.95,1.29)$ \\
\hline Myocardial infarction within last 7 days & 0.5033 & .0003 & 1.654 & $(1.26,2.17)$ \\
\hline Immune suppressive treatment & 0.1211 & .3512 & 1.129 & $(0.87,1.46)$ \\
\hline Chronic lung disease & 0.2207 & .0019 & 1.247 & $(1.08,1.43)$ \\
\hline Peripheral vascular disease & 0.1565 & .0907 & 1.169 & $(0.98,1.4)$ \\
\hline Smoker & 0.1204 & .0801 & 1.128 & $(0.99,1.29)$ \\
\hline Arrhythmia & 0.2640 & .0009 & 1.302 & $(1.11,1.52)$ \\
\hline Any valve repaired & -0.2786 & .0023 & 0.757 & $(0.63,0.91)$ \\
\hline
\end{tabular}

$\mathrm{C}$ index $=0.80046 . C I$, Confidence interval; IABP, intra-aortic balloon pumping; $C A B G$, coronary artery bypass grafting IDDM, insulin-dependent diabetes mellitus; NIDDM, non-insulin-dependent diabetes mellitus; NYHA, New York Heart Association. 
TABLE E2. Full logistic regression model and point estimate for operative mortality

\begin{tabular}{|c|c|c|c|c|}
\hline Parameter & Estimate & $P$ value & Odds Ratio & $95 \%$ CI \\
\hline \multicolumn{5}{|l|}{ Year of surgery } \\
\hline 2008 & -0.2267 & .1439 & 0.797 & $(0.59,1.08)$ \\
\hline 2007 & -0.4140 & .0034 & 0.661 & $(0.5,0.87)$ \\
\hline 2006 & -0.3723 & .0079 & 0.689 & $(0.52,0.91)$ \\
\hline 2005 & -0.3388 & .0214 & 0.713 & $(0.53,0.95)$ \\
\hline 2004 & -0.1622 & .2371 & 0.85 & $(0.65,1.11)$ \\
\hline 2003 & -0.0745 & .6212 & 0.928 & $(0.69,1.25)$ \\
\hline 2002 (reference) & 0.0000 & & 1 & $(1,1)$ \\
\hline Female gender & 0.4776 & $<.0001$ & 1.612 & $(1.38,1.89)$ \\
\hline Body surface area & 0.2144 & .2070 & 1.239 & $(0.89,1.73)$ \\
\hline Age & 0.0275 & $<.0001$ & 1.028 & $(1.02,1.03)$ \\
\hline Dialysis & 1.2246 & $<.0001$ & 3.403 & $(2.55,4.54)$ \\
\hline Renal failure/creatinine $>2$ without dialysis & 0.6545 & $<.0001$ & 1.924 & $(1.59,2.33)$ \\
\hline Normal creatinine (reference) & 0.0000 & & 1 & $(1,1)$ \\
\hline Urgent or emergency status without shock & 0.3700 & $<.0001$ & 1.448 & $(1.22,1.72)$ \\
\hline Emergency, salvage, or cardiogenic shock & 1.0594 & $<.0001$ & 2.885 & $(2.18,3.81)$ \\
\hline Congestive heart failure & 0.0225 & .7646 & 1.023 & $(0.88,1.19)$ \\
\hline Active endocarditis & 0.7332 & $<.0001$ & 2.082 & $(1.76,2.46)$ \\
\hline Preoperative inotropes or IABP & 0.5317 & $<.0001$ & 1.702 & $(1.38,2.1)$ \\
\hline One distal coronary anastomosis & 0.1799 & .0846 & 1.197 & $(0.98,1.47)$ \\
\hline Two distal coronary anastomoses & 0.3234 & .0208 & 1.382 & $(1.05,1.82)$ \\
\hline Three distal coronary anastomoses & 0.2683 & .1319 & 1.308 & $(0.92,1.85)$ \\
\hline Four or more distal coronary anastomoses & 0.6134 & .0102 & 1.847 & $(1.16,2.95)$ \\
\hline Multiple valve surgery & 0.8274 & $<.0001$ & 2.287 & $(1.88,2.78)$ \\
\hline Tricuspid valve surgery & 0.4257 & .0218 & 1.531 & $(1.06,2.2)$ \\
\hline Mitral valve surgery & 0.2420 & .0027 & 1.274 & $(1.09,1.49)$ \\
\hline Aortic valve surgery (reference) & 0.0000 & & 1 & $(1,1)$ \\
\hline Prior $\mathrm{CABG}$ & 0.2010 & .0717 & 1.223 & $(0.98,1.52)$ \\
\hline Prior valve surgery & 0.4156 & $<.0001$ & 1.515 & $(1.28,1.79)$ \\
\hline IDDM & 0.3728 & .0002 & 1.452 & $(1.19,1.77)$ \\
\hline NIDDM & 0.2984 & .0008 & 1.348 & $(1.13,1.6)$ \\
\hline NYHA class IV & 0.1773 & .0351 & 1.194 & $(1.01,1.41)$ \\
\hline African American race & 0.0723 & .4488 & 1.075 & $(0.89,1.3)$ \\
\hline Preoperative steroid administration & 0.1399 & .2740 & 1.15 & $(0.9,1.48)$ \\
\hline Hypertension & 0.1024 & .1881 & 1.108 & $(0.95,1.29)$ \\
\hline Myocardial infarction within last 7 days & 0.5033 & .0003 & 1.654 & $(1.26,2.17)$ \\
\hline Immune suppressive treatment & 0.1211 & .3512 & 1.129 & $(0.87,1.46)$ \\
\hline Chronic lung disease & 0.2207 & .0019 & 1.247 & $(1.08,1.43)$ \\
\hline Peripheral vascular disease & 0.1565 & .0907 & 1.169 & $(0.98,1.4)$ \\
\hline Smoker & 0.1204 & .0801 & 1.128 & $(0.99,1.29)$ \\
\hline Arrhythmia & 0.2640 & .0009 & 1.302 & $(1.11,1.52)$ \\
\hline Any valve repaired & -0.2786 & .0023 & 0.757 & $(0.63,0.91)$ \\
\hline
\end{tabular}

$\mathrm{C}$ index $=0.78295 . C I$, Confidence interval; IABP, intra-aortic balloon pump; IDDM, insulin-dependent diabetes mellitus; NIDDM, non-insulin-dependent diabetes mellitus. 